\title{
Atypical Maternal Cradling Laterality in an Impoverished South African Population
}

Barak Morgan, Xanthe Hunt, Jechil Sieratzki, Bencie Woll and Mark Tomlinson

Barak Morgan: Global Risk Governance Programme, Institute for Safety Governance and

Criminology, Law Faculty, University of Cape Town, South Africa. barakmorgan@gmail.com,

+27834176264, orcid.org/0000-0002

Bencie Woll: Division of Psychology and Language Sciences, University College London, 49 Gordon

Square, London WC1H 0PD. b.woll@ucl.ac.uk, +44-20-7679-8670, @Bencie.Woll,orcid.org//0000-

0002-3300-4775

Please fill in your details as mine are above (using this font).

Corresponding author: Barak Morgan, barakmorgan@gmail.com

The authors report no conflict of interest. 


\section{Atypical Maternal Cradling Laterality in an Impoverished South African Population}

Human studies consistently report a $60-80 \%$ maternal left cradling preference. The dominant explanation points to an engagement of the emotionally more-attuned right brain. In contrast, we found equal incidences of left (31.3\%), right (34.3\%) and no-preference (34.3\%) cradling in an impoverished South African population living under adverse conditions characterized by extreme dangers. We found striking differences on the Parenting Stress Index (PSI) between mothers with no cradling laterality preference and mothers with either a left or right preference. In several mammals a homologous left preference becomes stronger when acute threats prevail, rendering the rightwards shift we observed under dangerous conditions seemingly paradoxical. We propose this paradox can be resolved in terms of life-history strategy theory which predicts reduced parental investment in chronically dangerous environments. We interpret our high PSI score findings in no-preference cradlers as indicative of poorer, or at least ambivalent, maternal coping which many studies show is typically associated with reduced emotional sensitivity and responsiveness. We suggest that the latter may be a psychological mechanism mediating a partial withdrawal of parental investment in response to an enduringly adverse environment. To the best of our knowledge, this is the first study investigating cradling laterality preferences in an adverse socioeconomic environment.

Cradling; maternal; infant; poverty; adversity; Parenting Stress Index

\section{Introduction}

Studies in WEIRD (Western, Educated, Industrialised, Rich, Democratic) settings report that $65 \%$ or more mothers cradle their infants on the left side (Sieratzki \& Woll, 1996). A consistent left cradling bias has also been reported from non-WEIRD settings (Fleva \& Khan, 2015). For example 76\% of Yanomamo (Amazonian Indian tribe) women cradled on the left (Bolton, 1978) and in a South African study, almost $90 \%$ of women in Black, Coloured and Indian samples cradled on the left (Saling \& Cooke, 1978).

Numerous explanations for this bias have been suggested, including maternal handedness, and the proximity of the left side to the maternal heart. However, only one of these is empirically well supported: that left cradling is related to the fact that the left visual/aural/tactile field subserves the emotionally more sensitive right brain (Sieratzki \& Woll, 2002; Swain, Lorberbaum, Kose, \& Strathearn, 2007). Diverse evidence consistently links left cradling to the right brain's enhanced capacity for emotional processing (Fleva \& Khan, 2015; Sieratzki \& Woll, 2002; Todd \& Banerjee, 2016). When mothers were asked to hold a pillow to their chest they displayed no laterality bias until they were asked to imagine the pillow to be an infant, after which a left bias emerged (Weiland \& Sperber, 1970). Similarly, children with ASD, a condition associated with impaired inter-personal emotional functioning, showed no left bias whereas control children without ASD did (Pileggi, Malcolm-Smith, \& Solms, 2015).

The link between left cradling and emotional processing is strengthened by several studies showing reduced left bias in women experiencing emotional difficulties. In the last month of pregnancy, women who cradle on the left reported being more prepared for their 
motherhood and had a more positive body image compered to right cradlers (Fleva \& Khan, 2015).

Several studies have also found an association between non-left cradling and depression (reviewed by Fleva and Khan, 2015). However, the findings are inconsistent. One study found increased right-cradling in multi-time mothers with high levels of stress but the opposite in first-time mothers (Suter, Huggenberger, Blumenthal, \& Schachinger, 2011). Studies have also failed to find a consistent link between reduced left cradling and depression. Reissland et al. failed to find a left-sided cradling bias in depressed mothers (Reissland, Hopkins, Helms, \& Williams, 2009). Weatherill et al. (Weatherill, Almerigi, Levendosky, Bogat, \& Eye, 2004) found a non-significant right-sided bias in depressed mothers while Donnot et al. found newborn right-holding was related to depressive symptoms in bottle-feeding mothers but not in breastfeeding mothers (Donnot, Vauclair, \& Bréjard, 2008).

Maternal stress and depression is commonly higher in resource constrained settings. In a study in Cape Town, South Africa $34.7 \%$ of mothers living in poverty were diagnosed with major depression (DSM-IV) at two months postpartum (Cooper et al., 2009). A decade later, a screening study for antenatal and postnatal depression provided an opportunity to investigate cradling laterality in the same impoverished community. If a diminished left cradling preference is indicative of such stress or depression, then we may expect rates of right- or no-preference cradling to be higher in extreme contexts. To the best of our knowledge, no studies have explicitly investigated cradling laterality in socioeconomically deprived communities. The current study investigated the hypothesis that the prevalence of left cradling laterality would be lower amongst women with higher levels of stress and postpartum depressed mood.

\section{Methods}

\section{Population}

This observational study took place between October 2010 and March 2011 in Khayelitsha, a peri-urban settlement of between 500000 and 750000 people on the outskirts of Cape Town, South Africa, characterised by particularly high levels of unemployment and poverty. Participants were women older than 18 years of age participating in a study involving community health worker screening for postpartum depression (Tsai et al., 2014).

This parent study assessed the severity of antenatal and postnatal depressed mood and investigated the feasibility of using community health workers to screen for depression (Parent study ethical approval - Health Research Ethics Committee of Stellenbosch University N09-09-244). All mothers in the parent study whose infants were aged 15 weeks or less during the study period were eligible for inclusion. This age limit was used because cradling laterality becomes biased to the dominant hand side as infant size and weight become significant factors (Todd \& Banerjee, 2016). Informed consent was obtained from all mothers who agreed to participate in this sub-study - there were no refusals. Ethical 
approval for this sub-study was received from the Health Research Ethics Committee of Stellenbosch University (N10/10/321).

\section{Procedures}

All eligible mothers were visited in their homes by one of two isi-Xhosa-speaking research assistants. The research assistants administered a series of questionnaires (all translated into into isi-Xhosa). These were verbally administered while the mother was not actively caring for her baby or otherwise occupied. The mother's answers were recorded in writing.

\section{Measures}

\section{Demographic and health information}

Self-reported data for a range of demographic and health variables were collected by the parent study. Variables used in this sub-study were:

Highest education level, employment status, married or no cohabiting partner, monthly household income, home dwelling (formal brick building or informal shack, self-built without foundation from corrugated iron, wood, plastic and other waste materials), running water on site, flush toilet on site, electricity in home, mother went hungry in last week, children went hungry in last week, social grant amount, substance abuse, HIV status.

\section{Maternal mental health}

Depressed mood was assessed in the parent study at two weeks postpartum. The Xhosa version of the EPDS-10 was administered using survey software programmed into a mobile phone (Tomlinson et al., 2009, 2013) Among Xhosa-speaking women, several studies have supported the construct validity, criterion related validity, and factor structure of the EPDS-10 (De Bruin, Swartz, Tomlinson, Cooper, \& Molteno, 2004; Hartley et al., 2011; Lawrie, Hofmeyr, de Jager, \& Berk, 1998) and it has also been shown to have high sensitivity for detecting depressed mood in numerous other settings worldwide (Tsai et al. 2013). Post-natal depression was defined as an EPDS score of greater than 13, a criterion which has been validated as representing "probable depression" (Hartley et al., 2011).

\section{Feeding mode}

Feeding mode was assessed by self-report. Mothers were asked whether they fed their infants by breast feeding only, bottle feeding only, or a combination of breast and bottle feeding.

\section{Parenting Stress Index}

The Parenting Stress Index-Short Form (PSI-SF) was administered during the home visit 
(Abidin, 2012). The scale is designed for use with parents of children ranging from 1 month to 12 years of age. This scale has been used widely throughout the world (Anderson, 2008; Foucault \& Schneider, 2009; Leung, Leung, Chan, Tso, \& Ip, 2005; Oburu \& Palmerus, 2003), including prior use in South African populations (Moolla, 2012; Potterton, Stewart, \& Cooper, 2007). The PSI is verbally administered to caregivers during an interview, and responses to statements are recorded on a 5-point Likert scale (responses = strongly agree, agree, not sure, disagree, strongly disagree). The scale also rates parents' responses on a 5-point Likert scale regarding the frequency of stress related to parenting within the past 3 months $(1=$ Never; $5=$ Always). Items are summed to create a total score as well as four sub-scales: Parental Distress (PD), Dysfunctional Parent-Child Interaction (DPCI), Difficult Child (DC) and Defensive Responding (DR). In a recent study of women affected by intimate partner violence in in a similar population in Cape Town, the PSI-SF had strong internal consistency $(\mathrm{a}=0.88)$ (Moolla, 2012).

\section{Handedness}

The Edinburgh Handedness Inventory (Oldfield, 1971) comprises ten questions aimed at assessing hand dominance across a range of daily activities such as writing or drawing, throwing, using a scissors. The inventory has been used in African contexts before (Best \& Avery, 1999; De Agostini, Khamis, Ahui, \& Dellatolas, 1997). Scores of 7.5 or higher were regarded as right-handedness.

\section{Cradling laterality preference}

To assess cradling and holding laterality preferences we created a picture-guided cradling/holding laterality questionnaire. Participants were shown left and right handed versions of cradling and shoulder holding (Figure 1) and asked a series of oral questions. The cradling laterality results presented here are those recorded in response to the following questions:

- On which arm do you prefer to cradle him/her when you are sitting, standing or walking?

- On which arm do you prefer to cradle him/her when you are playing/talking with him/her?

- On which arm do you prefer to cradle him/her when you are comforting him/her because he/she is distressed?

- On which shoulder do you prefer to hold him/her when you are sitting, standing or walking?

In each case only one of three possible answers was recorded: Left, Right or NoPreference. 
Figure 1. Examples of pictures shown to mothers as part of the cradling and shoulder holding laterality questionnaire. Mirror images of the same pictures were used to depict the right-sided equivalents of cradling and shoulder holding.

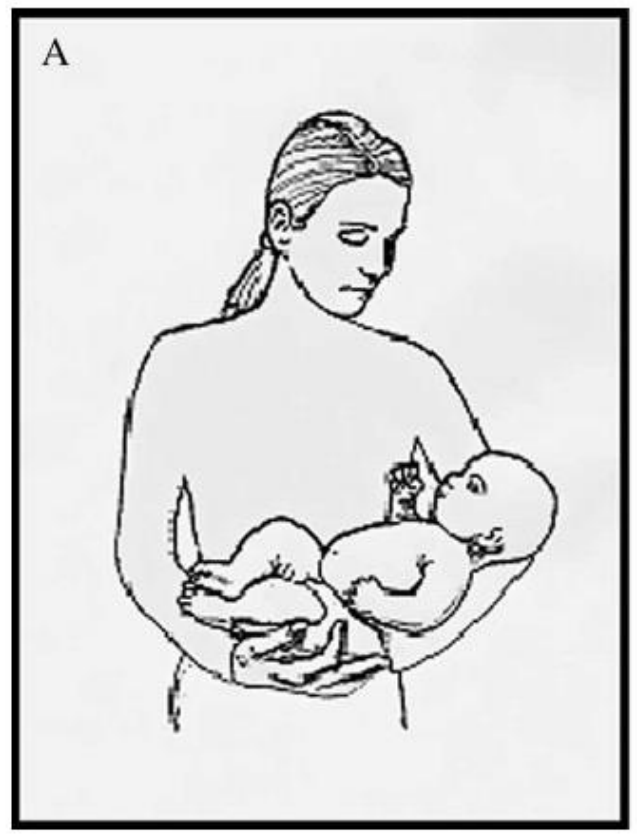

B

Figure 1. (A) left arm holding; (B) left shoulder holding.

\section{Data analysis}

Data analyses were conducted using SPSS. Pearson Correlation tests were used to assess consistency of laterality preferences across different holding conditions. Chi-squared tests were used to compare the number of participants in each feeding mode category or in each cradling laterality preference category. All continuous variables meeting normality criteria were analysed using ANOVA or t-test. One variable (Self-reported Stressful Life Circumstances) did not satisfy normality criteria and was analysed using non-parametric tests. All reported results are two-tailed.

\section{Results}

A total of 127 mothers with infants less than 15 weeks old were enrolled. Mothers $(n=7)$ whose Edinburgh handedness scale score was less than 0.75 were excluded. Among the 120 remaining mothers, infant age ranged from 3-103 days, average $=53.5$, median $=55.5$, standard deviation $=15.0$.

Table 1. Demographic information for the parent study sample $(n=1238)$ from which the cradling sub-study sample was drawn. 


\begin{tabular}{|l|c|}
\hline Mean highest education level & 10.3 years \\
\hline Completed school & $26 \%$ \\
\hline Unemployment & $81.2 \%$ \\
\hline Unmarried or no cohabiting partner & $43.4 \%$ \\
\hline Less than R2000 (USD150)/month household income & $53.2 \%$ \\
\hline $\begin{array}{l}\text { Informal housing (shack made without foundation from corrugated } \\
\text { iron, wood, plastic and other waste materials) }\end{array}$ & $68.7 \%$ \\
\hline No running water on site & $46.7 \%$ \\
\hline No flush toilet on site & $44.8 \%$ \\
\hline No electricity & $10.2 \%$ \\
\hline Mother went hungry in last week & $49.5 \%$ \\
\hline Children went hungry in last week & $29.1 \%$ \\
\hline
\end{tabular}

\section{Laterality}

Correlations between the mothers' answers to the four laterality questions were strong (Pearson's $r$ 0.365-0.531) and highly significant (all p<0.001). Cradling laterality preference across the whole sample showed a left dominance although this was not statistically significant (No-preference $=31 \%$, Left $=41 \%$, Right $=28 \%$, Chi sq $=3.15, \mathrm{p}=0.207$ ). Cradling laterality was not related to infant age $(\mathrm{F}=0.688, \mathrm{p}=0.504)$.

Exploratory analyses revealed that feeding mode distribution over the whole sample deviated significantly from statistical expectation $(\mathrm{Chi} \mathrm{sq}=10.85, \mathrm{p}=0.004)$. Feeding mode distribution over the whole sample showed that the largest group of mothers were exclusive bottle feeders followed by exclusive breast feeders. Mixed feeders were in the minority (Breast $=35.8 \%$, Breast and Bottle $=20 \%$, Bottle $=44.2 \%$ ). Feeding mode was not related to infant age $(\mathrm{F}=1.0, \mathrm{p}=0.371)$.

\section{Cradling and feeding}

We then examined cradling laterality according to feeding mode. No significant cradling preference differences were found between feeding modes $(\mathrm{p}=0.174)$. However, there was a significant difference in cradling preferences within bottle feeders (Table 2, Chi sq. $=9.321$, $\mathrm{p}=0.009)$ although not within breast or mixed feeders (all $\mathrm{p}>0.8)$.

Table 2. Cradling laterality according to feeding mode.

\begin{tabular}{|c|c|c|c|c|}
\hline & Bottle & $\begin{array}{l}\text { Mixed Breast \& } \\
\text { Bottle }\end{array}$ & Breast & $\begin{array}{l}\text { Pooled Breast + } \\
\text { Mixed Breast \& } \\
\text { Bottle }\end{array}$ \\
\hline No-preference & $14(26.4 \%)$ & $7(29.2 \%)$ & $16(37.2 \%)$ & $23(34.3 \%)$ \\
\hline Left & $28(52.8 \%)$ & $8(33.3 \%)$ & $13(30.2 \%)$ & $21(31.3 \%)$ \\
\hline Right & $11(20.8 \%)$ & $9(37.5 \%)$ & $14(32.6 \%)$ & $23(34.3 \%)$ \\
\hline
\end{tabular}


To further explore this finding of significantly increased left cradling in bottle feeders, we compared the three feeding modes on a range of demographic, psychosocial and health variables. No significant differences were found for age of baby, age of mother, social grant amount, home adversity, food adversity, substance abuse, household income (ANOVA, all p>0.109) or employment (Chi sq $=1.95, \mathrm{p}=0.378)$ and marital status (Chi sq $=0.07, \mathrm{p}=0.966)$. There were also no significant differences in depression, neither for total EPDS score nor for EPDS greater than 13 (EPDSgt13 Chi sq =1.18, $\mathrm{p}=0.554$ ), or for the Parenting Stress Index (PSI total and PSI sub-scales - Defensive Responding, Parental Distress, Difficult Child, Dysfunctional Parent-Child Interactions) (ANOVA, all p>0.193) and Self-reported Stressful Life Circumstances (Kruskal-Wallis H test $=4.64, p=0.098$ ).

At the time the study was done, mothers who tested positive for HIV were generally recommended not to breastfeed. We therefore investigated whether HIV status could account for the high proportion of exclusive bottle-feeding in our sample. A significant difference was found (Chi $\mathrm{sq}=50.5, \mathrm{p}<0.001)$ with a disproportionately higher number of mothers who did not breast feed at all being HIV positive (33 out of 53) while among breast feeders only 2 out of 43 mothers were HIV positive and zero out of 24 mixed feeders were HIV positive. There was however no significant difference in cradling preference between HIV positive and negative groups (Chi $\mathrm{sq}=0.133$, $\mathrm{p}=0.936$ ) or within each HIV group (all p> 0.395).

\section{Breast and mixed feeders compared to bottle feeders}

Since breast feeders and mixed feeders were similar in terms of HIV status and cradling laterality and differed markedly from bottle feeders in both these respects we pooled breast feeders and mixed feeders and compared them to bottle feeders. The difference in cradling laterality between these two groups approached significance (Chi sq. $=5.871$, $\mathrm{p}=0.053$ ) with the significant predominance of left cradlers among bottle feeders mentioned above not being present in pooled breast and mixed feeders (Chi sq $=0.119$, $\mathrm{p}=0.942$ ). Cradling preference among breast feeders and mixed breast/bottle feeders pooled together showed almost equal preferences for each cradling preference category (Table 2).

To check whether pooling breast feeders and mixed feeders was justified, we compared these two groups on a range of demographic and psychosocial variables. No significant differences were found for age of baby, age of mother, social grant amount, home adversity, food adversity, substance abuse, household income (ANOVA, all $\mathrm{p}>0.165$ ) or HIV status (Chi sq $=1.151, \mathrm{p}=0.283)$, employment (Chi $\mathrm{sq}=1.161, \mathrm{p}=0.688$ ) and marital status (Chi sq $=0.057, \mathrm{p}=0.881$ ). There were also no significant differences in depression (total EPDS score or EPDS greater than 13 (EPDSgt13 Chi sq $=0.147$, $\mathrm{p}=0.702)$ ), Parenting Stress Index (total and sub-scales) (ANOVA, all p>0.305) and Selfreported Stressful Life Circumstances (Mann-Whitney U test Z=-1.153, p=0.249) . We therefore continued to consider breast feeders and mixed feeders together as one group hereafter referred to as breast feeders while exclusive bottle feeders are hereafter referred 
to as non-breast feeders.

We compared these two groups - breast feeders and non-breast feeders - on all of the same demographic and psychosocial variables mentioned above. With the exception of maternal age (means, bottle $=28.1$, breast $=25.9$, $\mathrm{t}$-test, $\mathrm{t}=2.12, \mathrm{p}=0.036$ ) we found no other significant differences (ANOVA, all $\mathrm{p}>0.267$ ). To try to account for the marked difference in reported laterality of cradling preference between breast feeders and nonbreast feeders, we compared cradling preference within breast feeders and non-breast feeders for demographic differences and also in a hypothesis directed way for measures of depression and stress. Within non-breast feeders, there were no significant cradling differences in any of the following demographic measures: age of baby, age of mother, social grant amount, employment, home adversity, food adversity, substance abuse, household income (all p>0.221). HIV status, (Chi $s q=2.715$, $\mathrm{p}=0.257$ ). Similarly, within breast feeders (pooled breast feeder plus mixed feeder group), there were no significant cradling differences in any of the demographic measures mentioned above (all p>0.104). HIV status, $($ Chi $\mathrm{sq}=0.941, \mathrm{p}=0.625)$.

\section{Cradling, Depression and Stress}

The prevalence of depressed mood was 19.2\% (15.1\% for non-breast feeders and $22.4 \%$ ) for breast feeders). For the whole sample there was no significant association between cradling laterality and either total EPDS score $(\mathrm{F}=1.050, \mathrm{p}=0.541)$ or EPDS score greater than 13 (Chi $\mathrm{sq}=1.433, \mathrm{p}=0.488$ ). There were no significant differences between breast feeders and non-breast feeders for total EPDS score $(\mathrm{F}=0.337, \mathrm{p}=0.541)$ or EPDS score greater than $13(\mathrm{Chi} \mathrm{sq}=1.016, \mathrm{p}=0.313)$. Within non-breast feeders there was no significant association between cradling laterality and either total EPDS score $(\mathrm{F}=1.693$, $\mathrm{p}=0.196)$ or EPDS score greater than 13 (Chi $\mathrm{sq}=0.939, \mathrm{p}=0.625)$. Within breast feeders there was no significant association between cradling laterality and either total EPDS score $(\mathrm{F}=0.968, \mathrm{p}=0.386)$ or EPDS score greater than $13(\mathrm{Chi} \mathrm{sq}=0.322$, $\mathrm{p}=0.851)$.

The degree of Self-reported Stressful Life Circumstances was very low among both breast feeders (Chi sq. $=21.47, \mathrm{p}<0.001)$ and non-breast feeders (Chi sq. $=61.44$, $\mathrm{p}<0.001$ ) (Table 3). For breast-feeders and non-breast feeders, self-reported Stressful Life Circumstances scores did not differ significantly according to cradling preference (Kruskal-Wallis $\mathrm{H}=1.61$ and 5.53, $\mathrm{p}=0.447$ and 0.063 respectively).

Table 3. Number of breast feeding and non-breast feeding mothers in each category of Stressful Life Circumstances.

\begin{tabular}{|l|l|l|}
\hline & Non-Breast & Breast \\
\hline No & 22 & 38 \\
\hline Mild & 13 & 12 \\
\hline Moderate & 6 & 3 \\
\hline Severe & 2 & 2 \\
\hline
\end{tabular}


Within non-breast feeders, there were no significant cradling differences for Parenting Stress Index (PSI) scores (total PSI and PSI sub-scales). However, within breast feeders, there were significant cradling differences in total Parenting Stress Index score $(\mathrm{p}=0.014)$ and in 2 of the 4 subscales: DR, $\mathrm{p}=0.115$; PD, $\mathrm{p}=0.030$; DPCI, $\mathrm{p}=0.077$; $\mathrm{DC}, \mathrm{p}=0.028$ ). For total Parenting Stress Index and PSI sub-scales (Figure 2a-2e), nopreference cradlers always scored highest and Right cradlers always lowest except for PSI_DC where no-preference cradlers were highest and left cradlers were lowest. In all cases no-preference cradlers scored highest and in all but one case (Difficult Child), Right Cradlers scored lower than left cradlers (Figure 2). 
Figure 2. Graphs showing differences in PSI scores according to cradling preference.

Figure 2a. Mean total PSI scores according to cradling preference in breast feeders. Figure $2 \mathrm{~b}$. PSI defensive responding scores according to cradling preference in breast feeders.

Figure 2c. PSI parental distress scores according to cradling preference in breast feeders. Figure 2d. PSI dysfunctional parent-child interactions scores according to cradling preference in breast feeders.

Figure 2e. PSI difficult child scores according to cradling preference in breast feeders.
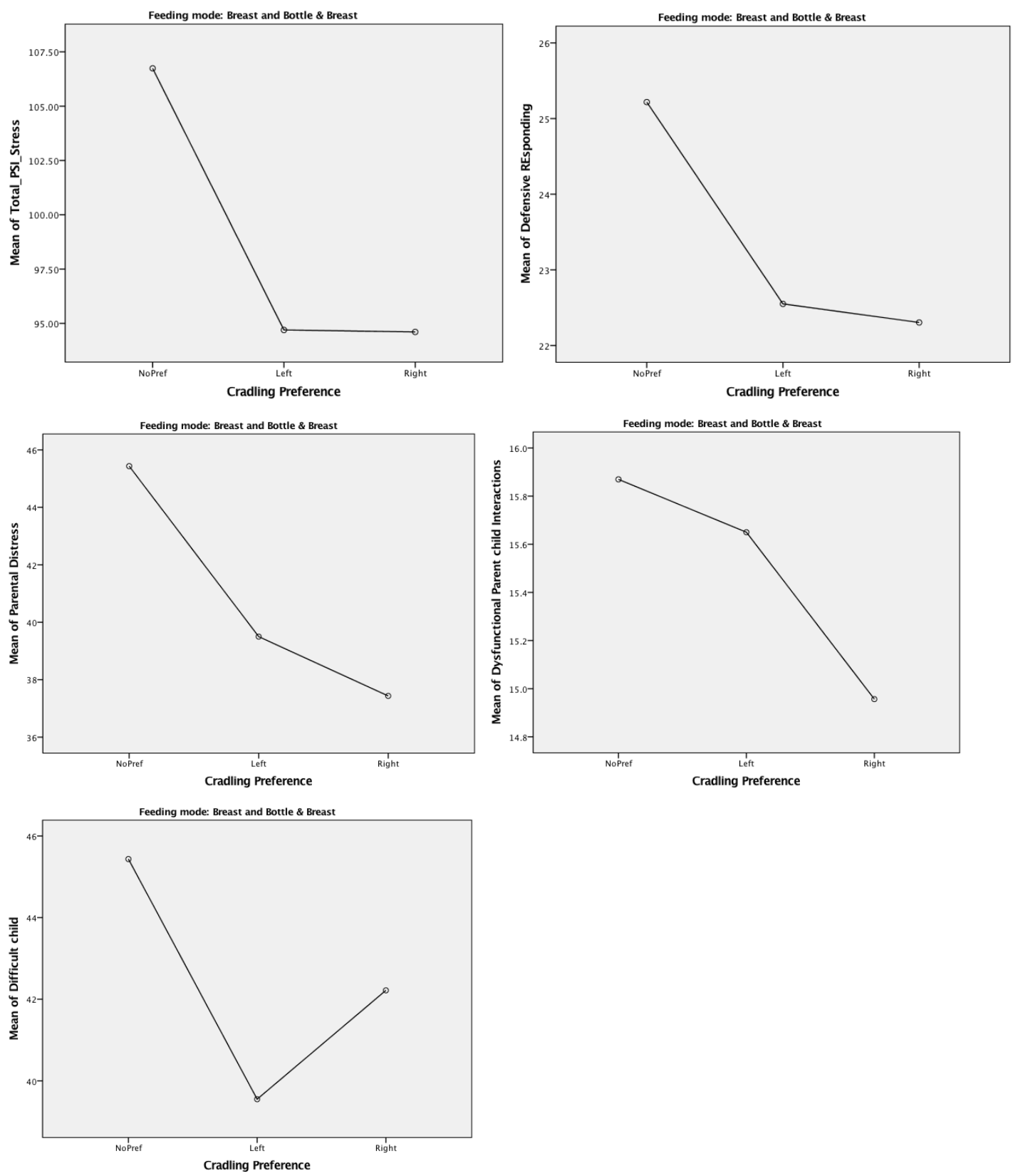
Pairwise contrasts showed that in all cases the significant or near-significant difference was between no-preference (higher) and either Left or Right (lower). In no cases did Left and Right Cradlers differ at a significant or near-significant level. For total Parenting Stress Index, no-preference was significantly higher than both Left and Right Cradlers (table 4).

Table 4. Pairwise contrasts for total PSI scores showing no-preference cradlers with significantly higher scores than both Left and Right cradlers who did not differ significantly from one another.

\begin{tabular}{|l|l|l|l|}
\hline & \multicolumn{1}{|c|}{ NP-Left } & \multicolumn{1}{|c|}{ NP-Right } & \multicolumn{1}{c|}{ Left-Right } \\
\hline & Mean difference & Mean difference & Mean difference \\
\hline $\begin{array}{l}\text { Total PSI } \\
\text { score }\end{array}$ & $12.04(\mathrm{p}=0.039)$ & $\begin{array}{l}12.13 \\
(\mathrm{p}=0.026)\end{array}$ & $\begin{array}{l}0.09 \\
(\mathrm{p}=1.00)\end{array}$ \\
\hline
\end{tabular}

\section{Discussion}

In contrast to the left-sided cradling bias reported in almost all other studies, we found equal incidences of left (31.3\%), ight (34.3\%) and no-preference (34.3\%) cradling in a South African population living under adverse socioeconomic conditions characterized by multiple stressors and real dangers. When we excluded exclusive bottle-feeders, twothirds of mothers were non-left cradlers. This in sharp contrast to all other studies we know of in which two thirds of mothers show a marked preference for left cradling.

The different patterns of cradling preferences seen between breast feeders (pooled exclusive breast feeders and mixed feeders) and non-breast feeders (exclusive bottle feeders) is puzzling. There is, to our knowledge, no evidence of an association between bottle feeding and left cradling. Furthermore, the fact that mixed feeders who bottle feed show the same cradling pattern as exclusive breast feeders suggests that bottle feeding per se does not explain the strong left cradling bias seen in exclusive bottle feeders in our sample. Equally this left bias does not appear to be related to any factor associated with exclusive bottle feeding (e.g. being HIV+). There was a significant age difference between and breast feeders and non-breast feeders but it is difficult to see how this could influence cradling preferences.

Although we cannot explain the striking difference in cradling preferences we found between breast feeders and non-breast feeders, the presence of this difference 
suggests two possibilities. One possibility is that the left cradling bias in the non-breast feeding group is the norm for our population as it is for most populations studied around the world. In this case, the absence of a left cradling bias in the breast feeding group represents a deviation from the norm. However, we found no evidence among any of the demographic or psychosocial measures to support this interpretation. In particular, neither depression nor stressful life circumstances accounted for the cradling findings in either the breast feeding or non-breast feeding group. The hypothesis that depression or stressful life circumstances are associated with a shift towards right cradling was therefore not supported in this population.

Another possible interpretation of our atypical cradling laterality findings in the breast feeding group is that the almost equal incidence of no-preference, left and right cradling in the breast feeding group is the norm for our population and that the left cradling bias seen in the non-breast feeders group represents a deviation from this norm. If so, one must ask why the Khayelitsha breast feeding norm is different to almost all other populations studied in both higher and lower income countries.

First, it can be noted that the proportion of right cradlers in our breast feeding group closely resembles that in almost all studies around the world $\left( \pm 1 / 3^{\text {rd }}\right)$. Consequently, relative to the predominant finding in the literature of at least $2 / 3 \mathrm{rds}$ left cradling, it would seem that our no-preference findings account for the overall shift towards right cradling. In other words, a large fraction of mothers who would be left cradlers in other populations are no-preference cradlers in our population.

We also found no association between cradling laterality preferences and adversity. However, this may reflect a floor effect, meaning that socioeconomic conditions are overwhelmingly adverse for all subjects. Indeed, the environment our population inhabited was severely impoverished and moreover, replete with dangers such as unsafe roads, exposed electricity cables, frequent fatal shack fires, extreme weather with frequent flooding, unsafe water, poor sanitation, drug and alcohol abuse, high incidences of diarrheal disease, HIV and tuberculosis, and endemic domestic, sexual and criminal gang violence. Mortality among both children and adults from infectious diseases, accidents, fires, knife and gunshot wounds is frequent, as is rape (Barbarin \& Richter, 2001; Cooper et al., 2009).

Karenina et al. recently reported a clear preference in 11 mammal species for leftlateralization between mothers and offspring. They interpret this as a left eye-right brain advantage in processing social-emotional information that helps mothers to optimally monitor their infants, especially under threatening conditions. Human studies consistently report a 60-80\% maternal left cradling preference independent of handedness, also supported by evidence of engaging the emotionally attuned right brain (Sieratzki \& Woll, 2002; Todd \& Banerjee, 2016). Considering these animal and human findings, our finding of a two-thirds non-left cradling bias in Khayalitsha mothers who breast feed appears paradoxical. In the face of danger animal mothers increase social-emotional engagement which reflects high parental investment in ensuring offspring survival and wellbeing, whereas our data suggests that under dangerous conditions human mothers 
decrease social-emotional engagement with their infants.

A possible explanation for this paradox may be found in life-history strategy theory (LHST). LHST is an evolutionary theory which predicts that under chronic harsh, unsafe conditions (as opposed to transient danger) such as our Khayalitsha mothers experience, organisms will make the most of current opportunities at the expense of longterm investment. This is known as adopting a fast life-history strategy (LHS) and includes as a central feature a reproductive strategy characterized by early, more frequent, more risky (unsafe sex, more promiscuity, more competitive) mating, early reproduction (teenage pregnancy) and more frequent childbearing with lower parental investment per child (Belsky \& Pluess, 2013; Ellis, Brumbach, \& Schlomer, 2009; Ellis \& Del Giudice, 2014). The major environmental drivers of a fast LHS are harshness (scarcity of resources), extrinsic mortality (premature deaths caused by factors outside personal control) and unpredictability (e.g. job insecurity, frequent accidents) (Ellis, Brumbach, \& Schlomer, 2009). All these drivers are strongly present in our study population and while we did not measure other indices of LHS, the population our sample was drawn from is characterized by multiple features of a fast LHS (Barbarin \& Richter, 2001; Belsky \& Pluess, 2013; Cooper et al., 2009; Ellis \& Del Giudice, 2014; Ellis, Figueredo, Brumbach, \& Schlomer, 2009).

As mentioned, a core feature of a fast LHS is less investment per child, i.e. preservation of maternal resources to produce many children exists as a strategy against high child mortality (Belsky \& Pluess, 2013; Ellis, Brumbach, et al., 2009; Ellis \& Del Giudice, 2014). The rightward shift in cradling among breast feeding mothers may therefore reflect sparing of maternal resources, i.e. reduced engagement of the emotionally attuned right brain is consistent with reduced sensitivity and responsiveness to the infant's communication of its physical and emotional needs. A range of sensitivity and responsiveness evidence strongly reinforces the idea that left cradling entails more emotional investment (hence, resources in general) in nurturing babies than non-left cradling does. With regard to sensitivity, Huggenberger et al. found non-left cradlers showed a lower sensitivity for positive emotional faces of babies than for negative ones, whereas left cradlers showed almost equally high sensitivity in detection of positive and negative emotional expressions (Huggenberger, Suter, Reijnen, \& Schachinger, 2009). Sensitivity to infant negative emotional states is much more crucial for survival than is sensitivity to positive states. Finding no difference between left and right cradlers for negative faces is therefore consistent with evolutionary theory. However, the better ability of left cradlers to identify positive expressions is consistent with the idea that they are more likely to invest extra resources engaging in a positive way with their babies than non-left cradlersare.

Extensive data also exist that support the idea that left cradlers are more emotionally responsive and feel more emotionally engaged with their babies than right cradlers are (Sieratzki \& Woll, 2002). For example, De Chateau reported that right cradling mothers were less sensitive to signals coming from the infant and more anxious and in need of nursing support (DeChateau, 1987). Salk found that $83 \%$ of mothers who experienced normal deliveries and contact with their infants immediately after birth were left-cradlers. 
In contrast, only $52 \%$ of mothers separated from their infants at birth because of prematurity or illness, left-cradled (Harris, 2010). Other studies, showed reduced or reversed left cradling bias in "emotionally uninvolved" mothers of newborns (DeChateau, Fitzgerald, \& Lester, 1991). Studies involving autism spectrum disorder are also instructive in this regard. Pileggi et al. found that only $48 \%$ of children with autism spectrum disorder exhibited a left cradling bias compared to $83 \%$ of normal controls (Pileggi et al., 2015). Fleva and Khan similarly found that adults high in autism spectrum traits and low in empathy traits were much more unlikely to cradle an experimental doll on the left (Fleva \& Khan, 2015).

While LHST offers an ultimate (why did something evolve?) explanation of our findings, we also found evidence of a proximal mechanism (how does it work?) (Laland, Sterelny, Odling-Smee, Hoppitt, \& Uller, 2011). No-preference mothers reported much higher Parenting Stress Index (PSI) scores than both left or right preference mothers while left and right preference mothers did not differ from each other (Figure 2 and Table 4). This finding may reflect a psychological mechanism whereby adverse environmental conditions reduce parental investment. Arguably, no-preference mothers are women who under favorable conditions would be left-cradlers but who, for intrinsic (e.g. personality) and/or extrinsic (e.g. domestic violence) reasons we either did not measure or failed to detect, felt subjectively less able to cope with their infant's needs and demands than leftcradlers in our sample (Cooper et al., 2009; Reissland et al., 2009) To minimize this subjective distress, no-preference mothers may tend to intermittently disengage emotionally from their infants by adopting a partial right-cradling preference, circumventing the emotional right brain (Rosenblum \& Andrews, 1994; Sieratzki \& Woll, 2002; Todd \& Banerjee, 2016). Being less attuned to their child's needs, nopreference mothers are thus likely also to invest less psychological, behavioural and material resources in nurturing individual offspring needs (Rosenblum \& Andrews, 1994; Sieratzki \& Woll, 2002; Todd \& Banerjee, 2016). In view of the negativity bias for infant emotion mentioned above, this may only apply when the infant is feeling positive emotions. This is also consistent with LHST because failure to respond to negative infant states is evolutionarily speaking too risky.

Similarly, the fact that right-cradlers did not score significantly higher than leftcradlers on either total PSI score or any PSI subscale score (figure 2a-e) suggests an absolute right cradling preference may minimize subjective distress by even more fully disengaging the right brain (Reissland et al., 2009; Sieratzki \& Woll, 2002; Todd \& Banerjee, 2016). In contrast, left cradlers report appreciable but perhaps manageable PSI stress levels; no-preference cradlers are arguably ambivalent about disengaging, and thus do not down-regulate subjective parenting stress as effectively as either left or right cradlers, and therefore have the highest PSI scores. This LHST interpretation of the findings might also explain the unexpectedly low levels of depression and stress found. The proposed function of a rightwards shift in cradling preference, i.e. preservation of emotional resources, could act as a protective buffer against depression and feelings of being overwhelmed by what are by all accounts objectively very stressful lifecircumstances. 
A limitation of this study is that cradling laterality preference was based on selfreport information rather than direct observation. The fact that the study was conducted in the women's homes made it impossible to standardise experimental conditions or make systematic observations. However, comparing various studies of cradling preference, self-report and observation indicates similar scores, whichever measure is used.

In summary, we found a starkly atypical cradling laterality bias in breast feeding women living in impoverished conditions. We found no evidence that cradling preferences were related to subjective measures of depression or stressful living conditions. We did however find a strong association between no preference cradling and high scores on the Parenting Stress Index. We suggest that the atypical cradling bias may in fact be typical for breast feeding women living in extremely adverse social and physical circumstances. Specifically, we hypothesize that relative to the norm of twothirds left and one third right cradlers reported in most studies, a shift by approximately half of left cradlers to become no-preference cradlers accounts for the observed one third left, one third no-preference and one third right cradling preference we observed in this impoverished population. We further hypothesize that this shift from left to no-preference is consistent with reduced maternal investment under adverse conditions as LHST predicts.

Finally, since cradling on the left or right per se arguably entails no other difference in fitness costs, cradling preference in human mothers might constitute an index of parental emotional resources.As such, cradling preference may possibly be an easily observable meaningful behavioural trait signaling possible maternal emotional disengagement and its well-known heightened risks for adverse child development outcomes (Cooper et al., 2009; Jones, 2014). This hypothesis could be tested by measuring other non-cradling indices of maternal investment in cradlers in our population as well as in safer, more privileged populations where the typical two-thirds left cradling bias prevails.

Abidin, R. R. (2012). Parenting Stress Index. Clinical Psychology (4th ed.). Lutz, FL: PAR.

Anderson, L. S. (2008). Predictors of Parenting Stress in a Diverse Sample of Parents of Early Adolescents in High-Risk Communities. Nursing Research, 57(5), 340-350. https://doi.org/10.1097/01.NNR.0000313502.92227.87

Barbarin, O. A., \& Richter, L. M. (2001). Mandela's children: Growing up in postapartheid South Africa. Mandela's Children: Growing up in Post-Apartheid South Africa. Retrieved from http://ovidsp.ovid.com/ovidweb.cgi?T $=\mathrm{JS} \& \mathrm{PAGE}=$ reference $\& \mathrm{D}=\mathrm{psyc} 3 \& \mathrm{NEWS}=\mathrm{N}$ \&AN=2001-18519-000

Belsky, J. A. Y., \& Pluess, M. (2013). Beyond risk, resilience, and dysregulation : Phenotypic plasticity and human development, 25, 1243-1261. https://doi.org/10.1017/S095457941300059X

Best, C. T., \& Avery, R. A. (1999). Left-Hemisphere Advantage for Click Consonants is 
Determined by Linguistic Significance and Experience. Psychological Science, 10(1), 65-70. https://doi.org/10.1111/1467-9280.00108

Bolton, R. (1978). Child holding patterns. Current Anthropology, 19(1), 134-135. https://doi.org/10.1086/ 202015

Cooper, P. J., Tomlinson, M., Swartz, L., Landman, M., Molteno, C., Stein, A., ... Murray, L. (2009). Improving quality of mother-infant relationship and infant attachment in socioeconomically deprived community in South Africa: randomised controlled trial. BMJ (Clinical Research Ed.), 338(apr14 2), b974. https://doi.org/10.1136/bmj.b974

De Agostini, M., Khamis, A. H., Ahui, A. M., \& Dellatolas, G. (1997). Environmental influences in hand preference: An African point of view. Brain and Cognition, 35, 151-167.

De Bruin, G. P., Swartz, L., Tomlinson, M., Cooper, P. J., \& Molteno, C. (2004). The factor structure of the Edinburgh postnatal depression scale in a South African periurban settlement. South Africa Journal of Psychology, 34(1), 113-121.

DeChateau, P. (1987). Left-side preference in holding and carrying new-born infants - a 3-Year Follow-Up-Study. Acta Psychiatrica Scandinavia, 75(3), 283-286.

DeChateau, P., Fitzgerald, H. E., \& Lester, B. M. (1991). Clinical application of asymmetrical behavioral communication in parentinfant interaction. In H. E. Fitzgerald, B. M. Lester, \& M. W. Yogman (Eds.), Theory and research in behavioral paediatrics (pp. 185-208). Plenum.

Donnot, J., Vauclair, J., \& Bréjard, V. (2008). Newborn right-holding is related to depressive symptoms in bottle-feeding mothers but not in breastfeeding mothers. Infant Behavior and Development, 31(3), 352-360. https://doi.org/10.1016/j.infbeh.2007.12.013

Ellis, B. J., Brumbach, B. H., \& Schlomer, G. L. (2009). Fundamental Dimensions of Environmental Risk. https://doi.org/10.1007/s12110-009-9063-7

Ellis, B. J., \& Del Giudice, M. (2014). Beyond allostatic load: rethinking the role of stress in regulating human development. Development and Psychopathology, 26(1), 1-20. https://doi.org/10.1017/S0954579413000849

Ellis, B. J., Figueredo, A. J., Brumbach, B. H., \& Schlomer, G. L. (2009). Fundamental Dimensions of Environmental Risk. Human Nature (Vol. 20). https://doi.org/10.1007/s12110-009-9063-7

Fleva, E., \& Khan, A. (2015). An examination of the leftward cradling bias among typically developing adults high on autistic traits. Laterality, 20(6), 711-722. https://doi.org/10.1080/1357650X.2015.1046881

Foucault, D. C., \& Schneider, B. H. (2009). Parenting values and parenting stress among impoverished village and middle-class small city mothers in the Dominican Republic. International Journal of Behavioral Development, 33(5), 440-450. https://doi.org/10.1177/0165025409340094

Harris, L. J. (2010). Side biases for holding and carrying infants: Reports from the past and possible lessons for today. Laterality (Vol. 15). https://doi.org/10.1080/13576500802584371

Hartley, M., Tomlinson, M., Greco, E., Comulada, W. S., Stewart, J., le Roux, I., ... Rotheram-Borus, M. J. (2011). Depressed mood in pregnancy: Prevalence and correlates in two Cape Town peri-urban settlements. Reproductive Health, 8(1), 9. 
https://doi.org/10.1186/1742-4755-8-9

Huggenberger, H. J., Suter, S. E., Reijnen, E., \& Schachinger, H. (2009). Cradling side preference is associated with lateralized processing of baby facial expressions in females. Brain and Cognition, 70(1), 67-72. https://doi.org/10.1016/j.bandc.2008.12.010

Jones, S. (2014). Maternal cradling bias and early communicative interactions: Implications for early identification of children at risk. Infant Behavior and Development, 37(4), 722-728. https://doi.org/10.1016/j.infbeh.2014.08.008

Laland, K. N., Sterelny, K., Odling-Smee, J., Hoppitt, W., \& Uller, T. (2011). Cause and Effect in Biology Revisited: Is Mayr's Proximate-Ultimate Dichotomy Still Useful? Science. https://doi.org/10.1126/science.1210879

Lawrie, T., Hofmeyr, G., de Jager, M., \& Berk, M. (1998). Validation of the Edinburgh Postnatal Depression Scale on a cohort of South African women. South African Medical Journal, 88, 1340-1344. Retrieved from http://dro.deakin.edu.au/view/DU:30071273

Leung, C., Leung, S., Chan, R., Tso, K., \& Ip, F. (2005). Child behaviour and parenting stress in Hong Kong families. Hong Kong Medical Journal.

Moolla, S. (2012). Parenting: risk and protective factors for mothers with a history of family violence. University of Cape Town.

Oburu, P. O., \& Palmerus, K. (2003). Parenting stress and self-reported discipline strategies of Kenyan caregiving grandmothers. International Journal of Behavioral Development, 27(6), 505-512.

Pileggi, L. A., Malcolm-Smith, S., \& Solms, M. (2015). Investigating the role of socialaffective attachment processes in cradling bias: The absence of cradling bias in children with Autism Spectrum Disorders. Laterality, 20(2), 154-170. https://doi.org/10.1080/1357650X.2014.948449

Potterton, J., Stewart, A., \& Cooper, P. (2007). Parenting stress of caregivers of young children who are HIV Positive. African Journal of Psychiatry, 10(4), 210-214. Retrieved from http://www.ncbi.nlm.nih.gov/pubmed/19588028

Reissland, N., Hopkins, B., Helms, P., \& Williams, B. (2009). Maternal stress and depression and the lateralisation of infant cradling. Journal of Child Psychology and Psychiatry and Allied Disciplines, 50(3), 263-269. https://doi.org/10.1111/j.14697610.2007.01791.x

Rosenblum, L. A., \& Andrews, M. W. (1994). Influences of environmental demand on maternal behavior and infant development. Acta Paediatrica, 83(s397), 57-63. https://doi.org/10.1111/j.1651-2227.1994.tb13266.x

Saling, M. M., \& Cooke, E.-W. (1978). Cradling and transport of infants by South African mothers: A cross-cultural study. Current Anthropology, 25, 333-335. https://doi.org/doi:10.1086/203140

Sieratzki, J. S., \& Woll, B. (2002). Neuropsychological and neuropsychiatric perspectives on maternal cradling preferences. Epidemiologia E Psichiatria Sociale, 11(3), 170176. https://doi.org/10.1017/S1121189X00005686

Sieratzki, J. S., \& Woll, B. (2002). With the right touch : how blind mothers cradle babies, 2002.

Sieratzki, J., \& Woll, B. (1996). Why do mothers cradle babies on their left? The Lancet, 347(9017), 1746-1748. https://doi.org/10.1016/S0140-6736(96)90813-2 
Suter, S. E., Huggenberger, H. J., Blumenthal, T. D., \& Schachinger, H. (2011). Differential effect of ill-being and chronic stress on cradling behavior of first and multi-time parents. Infant Behavior and Development, 34(1), 170-178. https://doi.org/10.1016/j.infbeh.2010.12.003

Swain, J. E., Lorberbaum, J. P., Kose, S., \& Strathearn, L. (2007). Brain basis of early parent-infant interactions: psychology, physiology, and in vivo functional neuroimaging studies. Journal of Child Psychology and Psychiatry, and Allied Disciplines, 48(3-4), 262-287. https://doi.org/10.1111/j.1469-7610.2007.01731.x

Todd, B. K., \& Banerjee, R. (2016). Lateralization of infant holding by mothers: A longitudinal evaluation of variations over the first 12 weeks. Laterality, 21(1), 1233. https://doi.org/10.1080/1357650X.2015.1059434

Tomlinson, M., Rotheram-Borus, M. J., Doherty, T., Swendeman, D., Tsai, A. C., Ijumba, P., ... Chopra, M. (2013). Value of a mobile information system to improve quality of care by community health workers. SA Journal of Information Management, 15(1). https://doi.org/10.4102/sajim.v15i1.528

Tomlinson, M., Solomon, W., Singh, Y., Doherty, T., Chopra, M., Ijumba, P., ... Jackson, D. (2009). The use of mobile phones as a data collection tool: A report from a household survey in South Africa. BMC Medical Informatics and Decision Making, 9(1), 51. https://doi.org/10.1186/1472-6947-9-51

Tsai, A. C., Tomlinson, M., Dewing, S., le Roux, I. M., Harwood, J. M., Chopra, M., \& Rotheram-Borus, M. J. (2014). Antenatal depression case finding by community health workers in South Africa: feasibility of a mobile phone application. Archives of Women's Mental Health, 17(5), 423-431. https://doi.org/10.1007/s00737-0140426-7

Weatherill, R. P., Almerigi, J. B., Levendosky, A. A., Bogat, G. A., \& Eye, A. Von. (2004). Is maternal depression related to side of infant holding ?, 28(5), 421-427. https://doi.org/10.1080/01650250444000117

Weiland, I. H., \& Sperber, Z. (1970). Patterns of mother-infant contact: The significance of lateral preference. Journal of General Psychology, 117, 157-165. 